\title{
ÉTICA PROFESIONAL DE LOS ABOGADOS. TEORÍA Y PRAXIS EN LA PROVINCIA DE CORRIENTES, ARGENTINA (2002-2014)
}

Lawyers ethics.

Theory and praxis in the province of Corrientes, Argentina (2002-2014)

Etica professionale degli avvocati.

Teoria e prassi nella provincia di Corrientes, Argentina (2002-2014)

"The first thing we do, let's kill all the lawyers". (William Shakespeare, Enrique VI, parte II, Acto 4 Escena 2, 77)

Mauricio Goldfarb ${ }^{1}$

Recibido: 28 de febrero de 2020

Aprobado: 24 de abril de 2020

Resumen: La ética profesional de los abogados es un tema a menudo subestimado por los propios operadores jurídicos. A pesar de la demanda cada vez más creciente por comportamientos no solo correctos desde el punto de vista técnico sino también moral, el objeto de estudio no ha sido especialmente considerado, especialmente en su funcionamiento efectivo. Este artículo hace hincapié en los aspectos relacionados con el desarrollo práctico del sistema disciplinario, exponiendo un sesgo punitivo respecto de los conflictos con el propio Poder Judicial, donde se observa una mayor efectividad y punición en comparación con los conflictos suscitados con los clientes y otros abogados.

1 Abogado, Especialista en Derecho Administrativo, Doctor en Derecho, Docente de Derecho Administrativo de la Universidad Nacional del Nordeste, Corrientes, Argentina. Correo electrónico: estudiogoldfarb@hotmail.com. 
Palabras clave: Derecho Administrativo sancionador; Colegios de Abogados; Clientes; Abogacía.

Abstract: The professional ethics of lawyers is an issue often underestimated by the legal operators themselves. Despite the growing demand for behavior not only correct from the technical point of view but also moral, the object of study has not been specially considered, especially in its effective functioning. This article emphasizes aspects related to the practical development of the disciplinary system, exposing a punitive bias regarding conflicts with the Judiciary itself (where greater effectiveness is observed), compared to conflicts between clients and other lawyers.

Keywords: Administrative Law; Bar Associations; Clients; Advocacy.

Sommario: L'etica professionale degli avvocati è un problema spesso sottovalutato dagli stessi operatori legali. Nonostante la crescente domanda di comportamenti non solo tecnicamente corretti ma anche morali, l'oggetto di studio non è stato particolarmente preso in considerazione, soprattutto nel suo efficace funzionamento. Questo articolo sottolinea gli aspetti legati allo sviluppo pratico del sistema disciplinare, esponendo un pregiudizio punitivo riguardo ai conflitti con la stessa Magistratura (dove si osservano una maggiore efficacia e punizione), rispetto ai conflitti sollevati con i clienti e altri avvocati.

Parole chiave: Diritto amministrativo sanzionatorio; Associazioni di avvocati; Clienti; Professione legale.

Para citar este artículo:

Goldfarb, M. (2020). "Ética profesional de los abogados. Teoría y praxis de la Provincia de Corrientes, Argentina (2002-2014)".

Prudentia Iuris, N. 90, pp. 27-57

DOI: https://doi.org/10.46553/prudentia.90.2020.pp.27-57

\section{Introducción}

El tema sobre el que versa este artículo es el procedimiento disciplinario profesional de los abogados ${ }^{2}$. Si bien existen muchas obras sobre ética y

2 Este artículo refleja parte del trabajo de campo realizado para la tesis doctoral del autor, titulada "Responsabilidad disciplinaria del abogado. Procedimiento administrativo y 
deontología profesional -generales y referidas especialmente a las profesiones jurídicas-, no existen, en cambio, trabajos que hayan estudiado el comportamiento efectivo de los tribunales de disciplina de los Colegios Públicos de Abogados. Desde clásicos como el de $\mathrm{Parry}^{3}$, hasta obras más modernas como las de Vigo ${ }^{4}$ o Andruet 5 , la doctrina se ha encargado de conceptualizar las cuestiones éticas generales, los principios éticos que deben guiar la conducta del abogado, los fundamentos filosóficos que sostienen dichos principios y los sistemas de control de la conducta profesional, pero sin incluir trabajos de campo de significación. Los trabajos sobre ética profesional de la abogacía en la Argentina que abordan aspectos cuantitativos de la materia son escasos. Tampoco se han publicado datos significativos respecto del desempeño de los Tribunales de Disciplina de los Colegios de Abogados, como lo hace notar Ciuro Caldani ${ }^{6}$.

El objeto de esta investigación no ha sido planteado desde el punto de vista de su eficacia. Existen estudios muy valiosos que hacen foco en los colegios profesionales y sus potestades públicas, pero tampoco consideran el funcionamiento efectivo de las normas disciplinarias, como el muy buen trabajo de Sesin y Chiacchiera Castro ${ }^{7}$.

En síntesis, el planteo que propongo en este trabajo de investigación resulta novedoso, al tratar la cuestión disciplinaria profesional considerándola dentro del marco teórico del Derecho Administrativo, haciendo foco en la relación entre el cliente y su letrado y teniendo en cuenta especialmente los datos relativos a la eficacia del sistema.

La estructura por seguir es la siguiente: luego de la descripción de la metodología, se desarrollan los aspectos teóricos del régimen disciplinario llevado a cabo ante los Colegios de Abogados, para luego exponer los resultados del trabajo de campo realizado en la unidad de análisis. Para culminar, se incluyen la discusión de los resultados y las conclusiones finales.

revisión judicial"; defendida con éxito en diciembre de 2017 en la Facultad de Derecho y Ciencias Sociales de la Universidad Nacional del Nordeste y recomendada para su publicación. La tesis fue dirigida por la Dra. Mirta Sotelo de Andreau y el Tribunal estuvo integrado por los Dres. Pablo Gallegos Fedriani, Martha Altabe de Lértora y José Horacio Grando.

3 Parry, A. (1940). Ética de la abogacía. Buenos Aires. Editorial Jurídica Argentina.

4 Vigo, R. (h). (1990). Ética del Abogado. Buenos Aires. Abeledo Perrot.

5 Andruet, A. (2001). Ejercicio de la abogacía y deontología del Derecho. Córdoba. Alveroni.

6 Ciuro Caldani, M. (2019). Manual de ética de la abogacía. Buenos Aires. Ediciones SAIJ.

7 Sesin, D.; Chicacchiera Castro, P. (2012). Los Colegios Profesionales - Régimen Jurídico Público. Santa Fe. Rubinzal Culzoni Editores. 


\section{Metodología}

El trabajo de investigación está compuesto de objetivos descriptivosanalíticos y no prescriptivos. La investigación está limitada a los límites geográficos de la Provincia de Corrientes, una de las 24 jurisdicciones locales de la República Argentina. El número de egresados universitarios en la provincia asciende a 24.883 (2,5\% del total de la población provincial a 2010). El total de abogados matriculados alcanza a 4325 a diciembre de 2014, según los datos informados por los Colegios de Abogados de la provincia. De este modo, la provincia cuenta con 411 abogados cada 100.000 habitantes, tasa que supera en un $11 \%$ a la media nacional (368 cada 100.000) ${ }^{8}$.

La muestra es representativa del funcionamiento del Tribunal de Disciplina del Colegio de Abogados, ya que contempla un período de trece años, desde su constitución en 2001 y puesta en funcionamiento en 2002, hasta diciembre de 2014, fecha límite de la recolección de los datos utilizados en la investigación, los que fueron procesados entre marzo de 2015 y marzo de 2016.

Si bien se trata de un solo tribunal, el relevamiento incluyó todos los procedimientos iniciados respecto de los matriculados en los 5 (cinco) Colegios Públicos de Abogados que existen en la Provincia de Corrientes entre 2002 y 2014 (un total de 420 expedientes administrativos). De este modo, aunque no existe una tarea estrictamente comparativa con otro Tribunal de Disciplina, la muestra es relevante, ya que cada Colegio representa a zonas diversas de la provincia, con realidades muy diferenciadas en lo social y en lo profesional. La unidad de análisis también es significativa, porque en el largo período en estudio, el Tribunal se fue renovando de manera total cada dos años, incluyendo en su conformación a más de 60 personas diferentes, lo que excluiría sesgos de tipo puramente personal en las decisiones.

El estado de los expedientes -especialmente en materia de finalización de procedimientos- refleja la situación a junio de 2016. También se realizaron entrevistas semiestructuradas con el personal dependiente del Tribunal de Disciplina y con todos los abogados que presidieron el Tribunal desde su constitución y hasta 2015 .

8 La Junta Federal de Cortes y Superiores Tribunales de las provincias argentinas y Ciudad Autónoma de Buenos Aires informan un número superior de abogados matriculados: 5607. La diferencia (de casi 1300) podría explicarse por los abogados que fueron matriculados ante el Superior Tribunal de Justicia de la Provincia y que luego no cumplieron el trámite de rematriculación ante el Colegio Público de Abogados. Ver los indicadores para todas las provincias en http://www.jufejus.org.ar/images/doc/ACTIVIDADES/Estadisticas/Publicaciones/ DATOS/PLANILLA\%202013.pdf. 
Los resultados de la investigación se exponen de manera objetiva, de modo que puedan ser verificados y eventualmente validados o refutados. El modelo de investigación que se propone puede ser replicado en otras jurisdicciones, y así contrastar los datos que se obtengan con los aquí expuestos, para confirmar o descartar que se trate de resultados análogos. Futuras investigaciones podrían también verificar si las tendencias descriptas en los resultados de este trabajo se han mantenido a posteriori del cierre de la recolección de datos.

El universo de expedientes tramitados ante el Tribunal de Disciplina, que forma el corpus de la investigación, fue revisado de modo personal, y clasificado de acuerdo a las siguientes variables:

a. Denunciante (tribunales y otros funcionarios, clientes, colegas, autodenuncia).

b. Tipo de infracción y bien jurídico afectado (administración de justicia, clientes, colegas).

c. Estado del trámite (terminado/pendiente) y resultado (absolución/ sanción).

d. Gravedad de la sanción (leve, intermedia y grave).

\section{La colegiación legal de los abogados}

La colegiación pública ha sido un reclamo histórico de los profesionales del Derecho en la Argentina, expresado en sucesivas conferencias, congresos y reuniones de abogados ${ }^{9}$. De ahí que la existencia de los Colegios Públicos de Abogados sea una realidad común a todas las provincias argentinas, como lo es en gran parte del mundo. En este marco, no se discute su carácter de personas públicas no estatales, ni las prerrogativas públicas que de ello se derivan ${ }^{10}$. La Corte Suprema de Justicia de la Nación argentina sostuvo esta posición en la causa "Colegio Público de Abogados de la Capital Federal c/ Martínez Echenique, Benjamín s/ cobro de pesos"11, del $1^{\circ}$ de septiembre de 1992. Allí, el máximo tribunal -con remisión al dictamen del Procurador General- resolvió lo siguiente:

9 Morello, A.; Berizonce, R. (1981). Abogacía y Colegiación. Buenos Aires. Hammurabi, 194.

10 Monti, L.; Muratorio, J. (1993). "La aplicación de la Ley Nacional de Procedimientos Administrativos a los actos de los entes públicos no estatales”. REDA, $\mathrm{N}^{\circ} 14$. Buenos Aires. Depalma.

11 Fallos: 315:1830. 
"El Colegio Público de Abogados no es una asociación (art. 14 de la Constitución Nacional) que se integra con la adhesión libre y espontánea de cada componente, sino una entidad destinada a cumplir fines públicos que originariamente pertenecen al Estado y que éste, por delegación circunstanciada normativamente, transfiere a la institución que crea para el gobierno de la matrícula y el régimen disciplinario de todos los abogados de la Capital Federal, como auxiliares de la administración de justicia".

En Argentina, las provincias conservan todo el poder no delegado en el Estado Federal al momento de sancionar la Constitución Nacional ${ }^{12}$. En virtud de estos poderes, las jurisdicciones locales pueden establecer límites y condiciones para el ejercicio de las profesiones liberales. Sin embargo, es importante señalar que esta regulación al ejercicio de los derechos no puede exceder dos límites fijados en la Constitución Nacional: el principio de reserva o intimidad del artículo 19 y el principio de razonabilidad del artículo $28^{13}$.

\section{Responsabilidad disciplinaria ante los Colegios de Abogados}

Como los Colegios de Abogados han sido investidos de la potestad de control de la disciplina de sus miembros, la responsabilidad disciplinaria surge cuando la conducta del abogado afecta el correcto ejercicio profesional, tanto dentro, como fuera de un proceso. Es, entonces, más amplia en su cobertura que la que desarrollan los tribunales y los órganos administrativos, quienes solo pueden sancionar una conducta incorrecta realizada ante sus propias oficinas, pero que carecen de potestad regulatoria en las relaciones entre abogado y cliente, por ejemplo, en su estudio particular.

La elevada exigencia ética que se impone a los abogados es la contrapartida de ciertos privilegios que la sociedad les ha otorgado. Se trata de los únicos autorizados para actuar ante los tribunales -a través de la exigencia de patrocinio letrado- y los únicos con un título que permite acceder a la magistratura y a otros cargos públicos de relevancia. En sus manos están

12 Constitución Nacional, "Artículo 121.- Las provincias conservan todo el poder no delegado por esta Constitución al Gobierno federal, y el que expresamente se hayan reservado por pactos especiales al tiempo de su incorporación".

13 Gelli, M. (2008). Constitución de la Nación Argentina. Comentada y concordada. T. I. Buenos Aires. La Ley, 89. Carnota, W. (2016). Instituciones de Derecho Público. $2^{\mathrm{a}}$ ed. Buenos Aires. La Ley, 116. Dromi, R. (2009). Derecho Administrativo, $12^{a}$ ed. act. Buenos Aires-MadridMéxico. Ciudad Argentina - Hispania Libros, 884. 
-todo el tiempo- la vida, la salud, la libertad y la propiedad de los ciudada$\operatorname{nos}^{14}$.

Ante la posible existencia de una falta ética se desarrolla un procedimiento específico, independiente de los otros tipos de responsabilidad (civil, penal o procesal), y que puede dar lugar a la aplicación de sanciones por órganos integrados por los propios letrados. Es posible que tenga lugar un doble juzgamiento -que no se reputa violatorio de la regla non bis in ídem por la independencia de los diferentes sistemas punitivos- en lo que hace al desempeño y la responsabilidad de los abogados por su accionar ante los estrados judiciales: por los propios tribunales y por el Tribunal de Disciplina del Colegio Público de Abogados ${ }^{15}$.

Esta potestad disciplinaria por faltas éticas es una facultad esencialmente administrativa, un poder otorgado por la Administración para la protección de un interés público. Así, las normas que regulan los aspectos éticos de la profesión de abogado no buscan tutelar los intereses particulares de los abogados, ni de los clientes y son claramente de naturaleza administrativa. Se trata de normas de Derecho Público, que tienen por objeto la protección de bienes que se consideran relevantes para el Estado: la competencia y la probidad de los auxiliares del servicio de justicia.

En el régimen que se analiza, el Estado provincial ha trasladado las funciones de contralor del ejercicio de la abogacía a organismos elegidos y gobernados por los propios abogados. La lógica del sistema parece clara: que sean los propios abogados los encargados de aplicar los premios a quienes cumplen adecuadamente con los mandatos legales y profesionales, así como los castigos a quienes actúan incorrectamente.

Como es evidente, este control de la matrícula delegado en los Colegios de Abogados no puede ser efectivo sin que existan facultades disciplinarias, necesarias para prevenir y reprimir posibles infracciones cometidas en el ejercicio de la abogacía. Especialmente prevenir, más que castigar, en virtud de la naturaleza pública de los bienes tutelados.

En lo que respecta a nuestra unidad de análisis, el Código de Ética del Colegio de Abogados de Corrientes establece expresamente el principio de heteronomía del sistema disciplinario, y la consiguiente indisponibilidad de los deberes y obligaciones profesionales, aún por medio de convenio privado $^{16}$.

14 Camps, C. (2002). "Derecho al debido proceso y ética profesional". JA, 2002-II, fascículo $\mathrm{N}^{\circ} 10$.

15 Gordillo, A. (1996). "La prescripción penal de una sanción administrativa". LL, 1996A, 625 .

16 Código de Ética del Colegio de Abogados de Corrientes, artículo $4^{\circ}$. 


\section{El caso de la Provincia de Corrientes}

En el caso de la unidad de análisis elegida, el proceso de colegiación legal tuvo sus particularidades. Si bien el Colegio de Abogados de Corrientes ya existía -como mera asociación civil-desde principios del siglo XX (1926), la colegiación legal y obligatoria llegó a nuestra provincia con demora en relación al resto del país, y a través de una norma jurídica de excepción. La colegiación obligatoria recién fue consagrada en 2001 -cuando ya regía en casi todas las otras provincias argentinas, con excepción de Chaco- y no fue producto de una decisión del cuerpo legislativo provincial, sino de un Decreto Ley ${ }^{17}$, dictado por la última intervención federal que sufrió la provincia.

El Decreto Ley $\mathrm{N}^{\circ} 119$ creó un colegio para cada circunscripción judicial, los que se integran formando el Colegio Público de Abogados de Corrientes, a cuya cabeza está el Consejo Superior del Colegio de Abogados ${ }^{18}$. En la actualidad, existen cinco circunscripciones judiciales en la Provincia de Corrientes. En consecuencia, existe el Colegio Público de Abogados de la Primera Circunscripción, el Colegio Público de Abogados de la Segunda Circunscripción, y así sucesivamente.

La propia norma que estableció la colegiación fijó en su artículo 118 los motivos para aplicar sanciones disciplinarias:

a) Condena judicial por delito doloso y todas aquellas que comprendan la de inhabilitación profesional.

b) Inhabilitación conforme a la Ley $\mathrm{N}^{0} 24.452$.

c) Violación de las prohibiciones y limitaciones establecidas por el artículo $3^{\circ}$ de la ley (que regula las incompatibilidades para el ejercicio profesional).

d) Retención indebida de documentos o bienes pertenecientes a sus mandantes, representados 0 asistidos.

e) Retardo o negligencia frecuente, ineptitud manifiesta u omisiones graves, en el cumplimiento de sus deberes profesionales.

f) Incumplimiento de las normas de ética profesional sancionadas por el Consejo Superior del Colegio de Abogados de la Provincia.

g) Toda contravención a las disposiciones del Decreto Ley de colegiación y al Reglamento Interno que sancionó al Consejo Superior del Colegio de Abogados de la Provincia.

17 Decreto Ley $\mathrm{N}^{\circ}$ 119, publicado en el Boletín Oficial de la provincia el 12-3-2001.

18 Decreto Ley No 119, "Artículo 45.- La totalidad de los Colegios de Circunscripción constituyen el Colegio de Abogados de la Provincia de Corrientes". 
Una primera lectura de la norma permite advertir que la enumeración de las faltas disciplinarias posee una textura muy abierta, propia del Derecho Administrativo Sancionador ${ }^{19}$, que, como destaca Nieto García, A. ${ }^{20}$, es ante todo Derecho Administrativo, por lo que corresponde la aplicación de las normas y principios de éste, con independencia de los principios propios del Derecho Penal. Este carácter abierto de la descripción usada por el legislador debe ser seguido de operaciones lógicas para la determinación de su alcance, como ocurre con la prestación del servicio con "eficiencia y eficacia", "actos de servicios compatibles con la función" o "beneficios", entre otros ${ }^{21}$.

La Corte Interamericana de Derechos Humanos tuvo ocasión de subrayar al respecto: "Aun cuando puede aceptarse que la precisión requerida en materia disciplinaria sancionatoria sea menor que en materia penal [...], el uso de supuestos abiertos o conceptos indeterminados, tales como la 'dignidad de la administración de justicia' o el 'decoro del cargo', requiere el establecimiento de criterios objetivos que guíen la interpretación o contenido que debe darse a dichos conceptos a efectos de limitar la discrecionalidad en la aplicación de las sanciones. Estos criterios pueden ser establecidos por vía normativa o por medio de una interpretación jurisprudencial que enmarque estas nociones dentro del contexto, propósito y finalidad de la norma, de forma tal de evitar el uso arbitrario de dichos supuestos, con base en los prejuicios o concepciones personales y privadas del juzgador al momento de su aplicación"22.

Por lo tanto, las conductas de los profesionales deben ser valoradas con un razonable margen de discrecionalidad, revisable en sede judicial, y sin que se admitan tipos penales en blanco, ni la extensión analógica de las infracciones ${ }^{23,24}$. Por ejemplo, en los incisos a) y b) ni siquiera se trata de una conducta, sino de una mera circunstancia de hecho: la existencia de una sentencia. Pero la aplicación de sanciones con motivo de sentencias penales firmes o inhabilitaciones solo será válida si es precedida de un proceso

19 Maljar, D. (2004). El Derecho Administrativo Sancionador. Buenos Aires. Ad Hoc, 71.

20 Nieto García, A. (2012). Derecho Administrativo Sancionador. $5^{\text {a }}$ ed. Madrid. Tecnos, 30 .

21 García Pullés, F. (2003). "Derecho Administrativo Sancionador y algunas notas del régimen disciplinario del empleo público", JA 2003-IV suplemento del fascículo 9.

22 Corte IDH, "Caso López Lone y otros vs. Honduras", pár. 272.

23 Balbín, C. (2014). Tratado de Derecho Administrativo. T. I. Buenos Aires. La Ley, 230.

24 En el mismo sentido, lo resuelto por la Cámara Nacional Federal en lo Contencioso Administrativo "A. D. c/ Colegio Público de Abogados", sentencia del 1-12-1999, citado por Altamira Gigena, J. (2008). Lecciones de Derecho Administrativo. $2^{a}$ ed. Córdoba. Advocatus, 32. 
disciplinario previo ${ }^{25,26}$. Sostener la validez de una sanción sin juicio previo y sin posibilidad de ejercer el derecho de defensa implicaría una flagrante violación al debido proceso, que acarrearía la nulidad de la sanción disciplinaria ${ }^{27}$. De igual modo, deberá procederse respecto de eventuales condenas civiles por daños y perjuicios por el incorrecto ejercicio de la abogacía ${ }^{28}$.

En los supuestos previstos en los incisos f) y g) hay, en cambio, una remisión a un conjunto normativo muy amplio, que debe integrarse en cada caso concreto. Además, las nociones de "negligencia frecuente", "ineptitud manifiesta" u "omisiones graves en el cumplimiento de sus deberes profesionales" solo pueden entenderse como conceptos jurídicos indeterminados que deberán ser analizados y revisados, en cada caso particular, por el Tribunal de Disciplina, y en su caso, por el juez, al revisar la actuación de éste ${ }^{29}$.

\section{Los deberes del abogado}

Tal cual estaba previsto en el inc. f) del artículo 118 del Decreto Ley de Colegiación, el Colegio Público de Abogados ha sancionado su propio Código de Ética. El Código tiene como fuente de inspiración el que sancionara el Colegio Público de Abogados de la Capital Federal, al cual reproduce casi textualmente, como puede advertirse de la simple lectura de ambas normas ${ }^{30}$.

25 Salgán Ruiz, L. (2011). "Las sanciones de plano y la problemática de su aplicación por la Administración Pública en el régimen disciplinario del contrato de empleo público. Avances y retrocesos del derecho administrativo disciplinario". Revista Argentina del Régimen de la Administración Pública-Rap: 395, Buenos Aires, Ediciones Rap, 2012.

26 En el mismo sentido, Ivanega, M. (2013). Cuestiones de potestad disciplinaria y derecho de defensa. $2^{\mathrm{a}}$ ed. Actualizada. Buenos Aires. Ediciones Rap, 157.

27 Como lo ha resuelto la Corte Suprema de Justicia de la Nación en la causa "Machado". En el mismo sentido, es muy ilustrativa la sentencia de la Cámara Nacional Federal en lo Contencioso Administrativo, Sala I, en la causa "Álvarez", donde se declaró la nulidad de una resolución de la propia Corte Suprema sobre la cesantía de una funcionaria judicial "Álvarez, Mónica Susana c/ Estado Nacional s/ empleo público", fallado el 7-4-2009, publicado en Rap 377:019).

28 Argumento inverso al que da Stiglitz, R. (2005). "Seguro contra la responsabilidad profesional". Revista de Derecho de Daños 2005-1. Santa Fe. Rubinzal Culzoni; y Kemelmajer de Carlucci, A. (2005). "Reflexiones sobre las normas deontológicas y la responsabilidad del abogado". Revista de Derecho de Daños 2005-1. Santa Fe. Rubinzal Culzoni, 48, que admiten a la infracción ética como presupuesto de la responsabilidad civil.

29 Sobre la utilización de conceptos jurídicos indeterminados, ver García de Enterría, Eduardo - Fernández, T. (2003). Curso de Derecho Administrativo. Madrid. Civitas. En la doctrina nacional, Sesin, D. (1996). Discrecionalidad administrativa y conceptos jurídicos indeterminados. Buenos Aires. Ciencias de la Administración, 294 y siguientes.

30 Textos completos en www.tdactes.org.ar y en www.cpacf.org.ar/formularios/codigoetica.pdf. 
A su vez, el Código de Capital Federal tiene como fuente principal y directa las Reglas de Ética de la Asociación del Foro de Nueva York, traducidas por Oscar Rodríguez Sarachaga en 1918.

\subsection{Deberes generales}

El Código de Ética establece ciertas obligaciones relacionadas con el orden jurídico en general, como "afianzar la justicia" o "preservar y profundizar el Estado de Derecho". También se incluyen otros deberes más concretos, como abstenerse de prestar servicio a la usurpación del poder político, tener domicilio fijo, no prestar su nombre para un estudio jurídico en el que no se participa y respetar rigurosamente el secreto profesional. Solo puede ser relevado del deber de confidencialidad cuando el propio cliente así lo autorice o si se trata de la propia defensa del letrado. Esta protección de la información obtenida en la relación entre cliente y abogado es de suma importancia, ya que hace a la esencia de la labor del profesional.

La Corte Suprema de Justicia de la Nación señaló que la denuncia de supuestos hechos ilícitos, efectuada por los abogados de quienes serían partícipes en ellos, y de los que habrían tomado conocimiento en razón de su vínculo profesional:

"Implica una violación no sólo al principio amplio de la defensa en juicio, sino de los derechos a la privacidad e intimidad de sus clientes, garantías que, deviniendo del artículo 19 de la Constitución Nacional, se cristalizan en normas tan claras y específicas como el artículo 244 del Código Procesal Penal de la Nación y del artículo 156 del Código Penal, y en otro orden no menos importante, en las disposiciones que regulan el ejercicio de la profesión de abogado, artículos $6^{\circ}$, inc. f) de la Ley $\mathrm{N}^{\circ} 23.187$, y 10 , inc. h) del Código de Ética del Colegio Público de Abogados de la Capital Federal. Si el deber de denunciar decae (aun en delitos contra la vida) cuando los hechos son conocidos bajo el amparo del secreto profesional, con mayor razón merece censura una presentación espontánea de quienes sin estar obligados a denunciar, y en violación de la prohibición de hacerlo, ponen en manifiesto hechos secretos que están obligados a guardar"31.

También le está prohibido al abogado realizar publicidad sin la mesura y el decoro propios de la dignidad de la profesión. La Cámara de Apelaciones en lo Contencioso Administrativo Federal se pronunció en autos "Barbato,

31 Del Dictamen del Procurador al que remitió la Corte, en autos "Clementi, Edgar Omar y otro vs. Embajada de Rusia y otros s/ cumplimiento de convenio de honorarios", sentencia del 17-4-2007. 
Myrian Edith y otro c/ CPACF s/ ejercicio de la abogacía Ley $\mathrm{N}^{\circ} 23.187$, art. 47", y confirmó una resolución del Tribunal de Disciplina del Colegio Público de Abogados de la Capital Federal que aplicó a dos abogados, como sanción, una advertencia en presencia del Consejo Directivo de acuerdo a lo establecido en el artículo 45, inciso b, de la Ley $\mathrm{N}^{\circ} 23.187$, por utilizar un colaborador que se presentaba como abogado y entregaba tarjetas del estudio jurídico de dichos profesionales ${ }^{32}$.

En el trabajo de campo realizado sobre nuestra unidad de análisis no se han registrado antecedentes de denuncias ni de sanciones aplicadas por infracciones a estos deberes generales.

\subsection{Deberes para con el Colegio de Abogados}

En el Código de Ética se establecen también algunas obligaciones del profesional para con el Colegio de Abogados. Entre ellas, aceptar los nombramientos de oficio, abonar la cuota anual y el derecho fijo por expediente, y en general, prestar colaboración para lograr los fines del Colegio.

En el caso de la falta de pago de la cuota anual, el Colegio está facultado para suspender la matrícula del deudor. Sin embargo, esta cuestión tiene un tratamiento distinto en los distintos Colegios que existen en la provincia, de acuerdo a la información recogida en las entrevistas realizadas a los presidentes de los Colegios de las cinco circunscripciones. En los Colegios del interior de la provincia, la falta de pago tiene como resultado la inhabilitación para el ejercicio profesional. En cambio, en el Colegio de la Primera Circunscripción -el mayor en número de miembros-, la falta de pago de la cuota anual no tiene consecuencia alguna respecto del ejercicio profesional efectivo. En el orden nacional, la doctrina y la jurisprudencia han señalado que la infracción a este deber debe considerarse en el contexto de las otras infracciones posibles, para evitar sanciones desproporcionadas $^{33}$.

En el trabajo de campo realizado sobre nuestra unidad de análisis no se han registrado antecedentes de denuncias ni de sanciones aplicadas por infracciones contra los Colegios de Abogados.

32 Fallo del 23 de julio de 2015.

33 “T. G. J. c/ Colegio Público de Abogados", CNFed. Contencioso Administrativo, Sala I, 6-4-2000. Ver el comentario de Fucito, F. (2000). "El pago de la matrícula profesional y la ética del abogado". LL 25-9-2000, 3. 


\subsection{Deberes para con los otros abogados}

En relación con los otros abogados, el Código obliga a respetar la dignidad de sus colegas y a hacer que la respeten. Algunas obligaciones principales que se establecen son la de comunicar fehacientemente al profesional que haya intervenido con anterioridad en el caso de reemplazo ${ }^{34}$ la prohibición de arribar a convenios con personas patrocinadas por otro profesional, sin la intervención o conocimiento de éste, y la de utilizar gestores para captar clientes. Asimismo, se establece la obligatoriedad del cumplimiento estricto de los acuerdos escritos o verbales que realice con sus colegas.

Del estudio de campo realizado, durante el período en estudio, las denuncias por faltas relacionadas con estos deberes fueron las siguientes:

Tabla 1

Denuncias de infracciones éticas contra otros abogados (2002-2014)

\begin{tabular}{|lrr|}
\hline Descripción de la falta & Cantidad & Porcentaje \\
\hline Falta de aviso al profesional que actuó en forma previa & 9 & $18 \%$ \\
Expresiones injuriosas para el colega - Faltas de respeto & 15 & $29 \%$ \\
Tráfico de influencias & 4 & $8 \%$ \\
Intervención indebida en el proceso & 5 & $10 \%$ \\
Incidentes en audiencias & 4 & $8 \%$ \\
Otras infracciones procesales & 14 & $27 \%$ \\
\hline Total & 51 & $100 \%$ \\
\hline
\end{tabular}

Fuente: Elaboración propia en base a registros del Tribunal de Disciplina.

\subsection{Deberes para con el cliente}

El abogado está obligado a decir siempre la verdad a su cliente y atender los intereses confiados con dedicación y celo. No debe crearle falsas expectativas, ni magnificar las dificultades, o garantizarle el buen resultado de su gestión profesional. El letrado debe considerar la propuesta del cliente de realizar consultas en situaciones complejas a profesionales especialistas, sin que ello sea tenido como una falta de confianza. No debe disponer de los bienes o fondos de su cliente -aunque sea temporalmente- $\mathrm{y}$, además, tiene

34 Este aviso no es necesario cuando el letrado anterior hubiera renunciado expresamente o se le hubiera notificado la revocación de tal mandato o patrocinio. 
que rendir cuenta oportuna de lo que perciba. Debe poner en conocimiento inmediato de su cliente las relaciones de amistad, parentesco con la otra parte, o cualquier otra circunstancia que razonablemente pueda resultar para el cliente un motivo determinante para la interrupción de la relación profesional.

Está obligado a realizar la tarea encomendada en forma personal, y solo puede sustituir su actuación por razones fundadas o de urgencia. También está obligado a mantener informado al cliente sobre el Tribunal u organismo donde tramite el asunto encomendado, su estado y marcha, siempre que éste se lo solicite.

Por supuesto, debe abstenerse de representar, patrocinar y/o asesorar, simultáneamente o sucesivamente, intereses opuestos en la misma causa, lo que además de una falta de disciplina profesional constituye el delito penal de prevaricato ${ }^{35}$. Por último, cuando un abogado renuncie al patrocinio o representación, debe cuidar que ello no sea perjudicial a los intereses de sus clientes, evitando en todo caso su desprotección.

Tabla 2

Denuncias por infracciones contra los derechos de los clientes (2002-2014)

\begin{tabular}{|lcc|}
\hline Descripción de la falta & Cantidad & Porcentaje \\
\hline Falta de información o comunicación & 54 & $33 \%$ \\
Cobró y no realizó el trabajo & 42 & $25 \%$ \\
Abandono de Defensa & 26 & $16 \%$ \\
Perención de instancia & 9 & $5 \%$ \\
Retiene dinero del cliente & 9 & $5 \%$ \\
Demora en el trámite & 8 & $5 \%$ \\
Otros conflictos por honorarios & 7 & $4 \%$ \\
Otras quejas sobre trato del profesional & 11 & $7 \%$ \\
\hline Total & 166 & $100 \%$ \\
\hline
\end{tabular}

Fuente: Elaboración propia en base a registros del Tribunal de Disciplina.

35 Código Penal argentino, "Artículo 271. - Será reprimido con multa de pesos dos mil quinientos a pesos treinta mil, e inhabilitación especial de uno a seis años, el abogado o mandatario judicial que defendiere o representare partes contrarias en el mismo juicio, simultánea o sucesivamente o que, de cualquier otro modo, perjudicare deliberadamente la causa que le estuviere confiada". 
Un dato aparece como muy significativo: considerando el total de denuncias, los conflictos entre abogado y cliente por cuestiones estrictamente patrimoniales (retención de dinero, cobro sin prestación posterior y otros conflictos sobre honorarios) no superan el $35 \%$ de las denuncias. Es decir que más de dos tercios de las quejas que recibe el sistema disciplinario no tienen una base estrictamente patrimonial. En cambio, los reclamos resultan de insatisfacción por otros aspectos, relacionados con una prestación deficiente del servicio, en especial, por falta de la debida información o diligencia en la tarea encomendada.

De los datos incluidos en la Tabla 2 se advierte también que una cantidad significativa de los conflictos (un tercio del total) corresponde a inconvenientes en la comunicación entre el abogado y su cliente. Estos problemas de la falta de comunicación (personal, telefónica, por mensajería) puedan hacer creer al cliente que el abogado no se interesa en su asunto, desgastando el vínculo profesional y la confianza en el letrado ${ }^{36}$. A pesar de que no puede siquiera pensarse en abogados sin clientes, los técnicos jurídicos son muchas veces expertos en contratos de compra venta, locación o donación, pero rara vez en el contrato que les brinda su sustento: el que se celebra entre cliente y abogado $^{37}$.

\subsection{Deberes respecto de la administración de justicia ${ }^{38}$}

Por último, se incluyen algunas obligaciones relacionadas en forma directa con la actuación ante los tribunales. Así, al abogado le está vedado incurrir en expresiones agraviantes respecto de magistrados, funcionarios o empleados; efectuar desgloses, o retirar expedientes, copias o actuaciones sin recibo o autorización. Además, en sus presentaciones y escritos judiciales, el abogado no puede valerse a sabiendas de pruebas falsas, ni tampoco incurrir en temeridad o malicia. También le está prohibido efectuar citas doctrinarias o jurisprudenciales inexistentes, o exponerlas en forma tal que falseen la opinión o el fallo invocado.

El detalle de las infracciones denunciadas en el período en estudio arroja los siguientes resultados:

36 Serna Orts, V. (2013). La relación del abogado con el cliente: La confianza y actuaciones que la traicionan. Revista de la Facultad de Ciencias Sociales y Jurídicas de Elche. Volumen I. Número 9.

37 Ampliar en AA. VV. (2006). “¿Por qué es importante que se brinde un espacio al tratamiento de temas relacionados con la Ética y Responsabilidad Profesional de los Abogados?”. Revista Ius et Veritas, $\mathrm{N}^{\circ} 33,418$ y sigs.

38 Artículos 22 al 24 del Código de Ética. 
Tabla 3

Infracciones denunciadas por magistrados (2002-2014)

\begin{tabular}{|lcr|}
\hline Descripción de la falta & Cantidad & Porcentaje \\
\hline Adulteración Boletas de Depósito & 39 & $25 \%$ \\
Frases injuriosas & 38 & $24 \%$ \\
Extravío de expedientes & 14 & $9 \%$ \\
Abuso de Recusación & 10 & $6 \%$ \\
Prevaricato & 7 & $4 \%$ \\
Escritos infundados reiterados & 7 & $4 \%$ \\
Falta de respeto al magistrado & 4 & $3 \%$ \\
Faltas contra funcionarios distintos de magistrados & 15 & $9 \%$ \\
Otras inconductas procesales & 14 & $9 \%$ \\
Incidentes en audiencias o mandamientos & 11 & $7 \%$ \\
\hline Total & 159 & $100 \%$ \\
\hline
\end{tabular}

Fuente: Elaboración propia en base a registros del Tribunal de Disciplina.

\section{Los resultados del trabajo de campo}

Expuesto el marco teórico y las infracciones que tienen previsión normativa, corresponde ahora verificar cómo se comporta en la práctica el sistema disciplinario, para revisar cuál es la respuesta a las infracciones que son objeto de juzgamiento, así como cuál es el resultado de los procedimientos cumplidos ante el Tribunal de Disciplina.

\subsection{El número de procedimientos terminados}

El número de procedimientos terminados sobre el total de iniciados debe considerarse en términos totales, y considerando la evolución año por año. Del total de 412 procedimientos iniciados, a diciembre de 2014 solo se hallan concluidos 267 , un $65 \%$ del total.

Sin embargo, este porcentaje total tiene un rango porcentual interanual muy alto. Los procedimientos más antiguos se hallan terminados en su totalidad para los primeros tres años (2002-2004) y con tasas muy altas (95\% al $89 \%$ ) en cuatro de los cinco años siguientes (con la excepción de 2008). Luego presentan una caída notoria en los porcentajes de finalización en los siguientes cuatro años del período estudiado del $61 \%$ al $45 \%$ en 2008 y 2010/2012. Finalmente, en los dos últimos años, los porcentajes de proce- 
dimientos finalizados caen al $25 \%$ y al $9 \%$, para el penúltimo año y para el último año (2013/2014).

Esta variación de los porcentajes resulta lógica considerando que los procedimientos más antiguos tienen más tiempo para resolverse y que los asuntos deben considerarse dando prioridad a los más antiguos. Sin embargo, como veremos más adelante, esta caída sostenida en el número de los procesos finalizados tiene también relación con la cantidad absoluta y relativa de sanciones aplicadas. La evolución de la cantidad de procesos terminados a partir del último tercio del período en estudio es un campo para futuras investigaciones, que verifiquen el mantenimiento o no de la tendencia que se evidencia en los últimos años.

\subsection{La cantidad de sanciones}

Así como destaqué las variaciones en los porcentajes de procesos disciplinarios terminados, la cantidad de sanciones aplicadas también registra variaciones en el tiempo. Si se considera el número absoluto de sanciones, el total de 131 expedientes con sanciones se reparte a lo largo de doce de los trece años -con excepción del último año, donde no se registran sanciones-, en un rango muy amplio entre 2 y 29 sanciones aplicadas por año, con un promedio de 13 expedientes terminados con sanciones por año para todo el período de estudio (2002-2014).

Sin embargo, la cantidad absoluta debe ser evaluada en relación al total de procesos iniciados. Así, se advierte que los porcentajes de sanciones sobre procedimientos iniciados forma una curva ascendente desde el inicio (primer año $28 \%$ ), que se estabiliza en los cuatro años posteriores (2003/2006) en el orden del $46 \%$ al $61 \%$. Luego de alcanzar un pico del $82 / 83 \%$ en $2007 / 2008$, comienza a decrecer de manera regular a partir de ese momento. En los dos años siguientes (2009/2010), los procedimientos que terminaron con sanción caen a porcentajes muy inferiores al pico, pero similares al período anterior (entre $48 \%$ y $57 \%$ en $2009 / 20100$, contra $46 \%$ al $61 \%$ en 2003/2006). Estos porcentajes de sanciones sobre procesos (entre el $45 \%$ y $60 \%$ ) marcan la moda, ya que incluyen seis de los trece años de estudio.

En la última fracción de cuatro años, los porcentajes decaen a niveles similares al del primer año (27\% y $25 \%$ para 2012/2013) y a niveles casi nulos (12\% y $0 \%$ de sanciones para los dos años restantes, 2011 y 2014 , respectivamente). 
Tabla 4

Procedimientos iniciados y con sanción (2002-2014). Totales absolutos y relativos

\begin{tabular}{|ccccccc|}
\hline Año & Iniciados & Terminados & Sanciones & $\begin{array}{c}\text { Sanciones } \\
\text { s/terminados }\end{array}$ & $\begin{array}{c}\text { Sanciones } \\
\text { s/iniciados }\end{array}$ \\
\hline 2002 & 25 & 25 & $\mathbf{1 0 0} \%$ & 7 & $28 \%$ & $28 \%$ \\
2003 & 26 & 26 & $\mathbf{1 0 0} \%$ & 12 & $46 \%$ & $46 \%$ \\
2004 & 18 & 18 & $\mathbf{1 0 0 \%}$ & 10 & $56 \%$ & $56 \%$ \\
2005 & 17 & 16 & $94 \%$ & 9 & $56 \%$ & $53 \%$ \\
2006 & 19 & 18 & $95 \%$ & 11 & $61 \%$ & $58 \%$ \\
2007 & 27 & 24 & $89 \%$ & 20 & $\mathbf{8 3} \%$ & $\mathbf{7 4} \%$ \\
2008 & 18 & 11 & $61 \%$ & 9 & $\mathbf{8 2} \%$ & $50 \%$ \\
2009 & 56 & 51 & $91 \%$ & 29 & $57 \%$ & $52 \%$ \\
2010 & 47 & 27 & $57 \%$ & 13 & $48 \%$ & $28 \%$ \\
2011 & 58 & 26 & $45 \%$ & $\mathbf{3}$ & $\mathbf{1 2} \%$ & $\mathbf{5 \%}$ \\
2012 & 37 & 22 & $59 \%$ & $\mathbf{6}$ & $\mathbf{2 7} \%$ & $\mathbf{1 6} \%$ \\
2013 & 32 & 8 & $25 \%$ & $\mathbf{2}$ & $\mathbf{2 5} \%$ & $\mathbf{6 \%}$ \\
2014 & 32 & 3 & $\mathbf{9} \%$ & $\mathbf{0}$ & $\mathbf{0 \%}$ & $\mathbf{0} \%$ \\
\hline Totales & 412 & 275 & $67 \%$ & 131 & $48 \%$ & $32 \%$ \\
\hline
\end{tabular}

Fuente: Elaboración propia en base a registros del Tribunal de Disciplina.

De acuerdo con los datos volcados en la tabla anterior resulta notoria la disminución en la tasa de sanciones aplicadas en los últimos cuatro años, donde el rango se sitúa entre el $0 \%$ y el $16 \%$, con dos años que registran 5 $\%$ y $6 \%$, respectivamente.

\subsection{El tipo de sanciones aplicadas}

En el análisis cuantitativo de las sanciones aplicadas, los resultados son los siguientes: 
ÉTICA PROFESIONAL DE LOS ABOGADOS. TEORÍA Y PRAXIS EN LA PROVINCIA...

Tabla 5

Total de sanciones aplicadas por el Tribunal de Disciplina (2002-2014)

\begin{tabular}{|lcc|}
\hline Sanción & Cantidad & Porcentaje \\
\hline Llamado atención & 12 & $9 \%$ \\
Multa & 7 & $5 \%$ \\
Suspensión de la Matrícula & $\mathbf{1 1 2}$ & $\mathbf{8 5 \%}$ \\
Exclusión de la Matrícula & 0 & $\mathbf{0 \%}$ \\
\hline Total & 131 & $100 \%$ \\
\hline
\end{tabular}

Fuente: Elaboración propia en base a registros del Tribunal de Disciplina.

Del examen de la tabla anterior se advierte una clara prevalencia de la sanción de suspensión (desde 1 día a 1 año) por sobre todas las otras sanciones. De todos modos, resulta claro que la gravedad de la suspensión en el ejercicio profesional se relaciona directamente con su duración. El Decreto Ley de colegiación contiene una clasificación bipartita en sanciones leves (apercibimiento y multa) y graves (suspensión y exclusión de la matrícula). A pesar de estas categorías legales, propongo una clasificación tripartita en sanciones leves (llamado de atención, multa y suspensión hasta 5 días), graves (suspensión de más de 5 días, pero inferior a 30 días) y muy graves (suspensión por más de 30 días y hasta 1 año).

Tabla 6

Detalle de las sanciones según su gravedad (2002-2014)

\begin{tabular}{|lcl|}
\hline Gravedad & Cantidad & \multicolumn{1}{c|}{ Detalle } \\
\hline Leves & $\mathbf{7 5}$ & Llamados de atención (12) Multas (7) \\
& $(\mathbf{5 7 \% )}$ & $\begin{array}{l}\text { Suspensiones de hasta 5 días (56) } \\
\text { Graves }\end{array}$ \\
& 30 & Suspensiones de + de 5 días y - de 30 días \\
Muy graves & $(23 \%)$ & \\
& 26 & Sanciones de 30 días o más \\
& $(20 \%)$ & \\
\hline Total de expedientes & 131 & \\
& $(100 \%)$ & \\
\hline
\end{tabular}

Fuente: Elaboración propia en base a registros del Tribunal de Disciplina. 
De acuerdo a los datos de la tabla anterior, se aprecia un número muy significativo de las sanciones de suspensión que fueron aplicadas por períodos cortos y solo en pocos casos (26 sobre $112,20 \%$ ) se aplicaron sanciones realmente muy graves (de 30 días o más).

Esta cantidad de suspensiones aplicadas ha sido considerada sobre el total de los expedientes con sanciones aplicadas (131). Veamos ahora qué ocurre cuando comparamos estas sanciones graves con el total de denuncias realizadas y con el total de expedientes terminados. Como detallé más arriba, sobre un total de 412 denuncias realizadas en el período 2002-2014 han concluido su trámite 267 . Entonces, la tasa de sanciones graves y muy graves es de 56/412 (14 \%) considerando el total de denuncias y de 56/267 $(21 \%)$ considerando el total de expedientes terminados.

\subsection{La cantidad relativa de sanciones aplicadas}

El análisis de la cantidad de sanciones aplicadas, y en particular su relación con la cantidad de abogados, nos lleva a preguntarnos sobre la significación del número de sanciones dentro del sistema disciplinario. Para ello, resulta necesario establecer pautas objetivas para cuantificar el significado de las sanciones aplicadas.

El primer paso para evaluar el significado de la cantidad de procedimientos iniciados y de sanciones aplicadas es considerar el número total de sujetos del sistema. El número de abogados informado por los Colegios de Abogados de la provincia evolucionó de manera ascendente y constante durante todo el período en estudio. Desde un inicio con solo 420 matriculados en 2002, el total de abogados alcanzó a 4325 a diciembre de 2014.

Propongo entonces comparar el crecimiento del universo de abogados en nuestra unidad de análisis, con el fin de obtener una tasa de sanciones por año. 
ÉTICA PROFESIONAL DE LOS ABOGADOS. TEORÍA Y PRAXIS EN LA PROVINCIA...

Tabla 7

Tasa de abogados imputados y sancionados por año (2002-2014)

\begin{tabular}{|cccccc|}
\hline Año & $\begin{array}{l}\text { Expedientes } \\
\text { iniciados }\end{array}$ & $\begin{array}{l}\text { Expedientes } \\
\text { con sanción }\end{array}$ & $\begin{array}{l}\text { Abogados } \\
\text { matriculados }\end{array}$ & $\begin{array}{l}\text { Abogados } \\
\text { imputados }\end{array}$ & $\begin{array}{l}\text { Abogados } \\
\text { sancionados }\end{array}$ \\
\hline 2002 & 25 & 7 & 460 & $5,43 \%$ & $1,52 \%$ \\
2003 & 26 & 12 & 822 & $3,16 \%$ & $1,46 \%$ \\
2004 & 18 & 10 & 1116 & $1,61 \%$ & $0,90 \%$ \\
2005 & 17 & 9 & 1420 & $1,20 \%$ & $0,63 \%$ \\
2006 & 19 & 11 & 1732 & $1,10 \%$ & $0,64 \%$ \\
2007 & 27 & 20 & 1991 & $1,36 \%$ & $1,00 \%$ \\
2008 & 18 & 9 & 2279 & $0,79 \%$ & $0,39 \%$ \\
2009 & 56 & 29 & 2553 & $2,19 \%$ & $1,14 \%$ \\
2010 & 47 & 13 & 2881 & $1,63 \%$ & $0,45 \%$ \\
2011 & 58 & 3 & 3291 & $1,76 \%$ & $0,09 \%$ \\
2012 & 37 & 6 & 3634 & $1,02 \%$ & $0,17 \%$ \\
2013 & 32 & 2 & 3963 & $0,81 \%$ & $0,05 \%$ \\
2014 & 32 & 0 & 4325 & $0,74 \%$ & - \\
\hline Promedios $\%$ & 31 & 10 & 2343 & $1,75 \%$ & $0,65 \%$ \\
\hline
\end{tabular}

Fuente: Elaboración propia en base a registros del Tribunal de Disciplina.

Los datos volcados en la tabla anterior evidencian que la tasa de abogados sometidos a procedimientos disciplinarios y efectivamente sancionados muestra un rango muy amplio, pero casi siempre decreciente (salvo el pico de 2009 ), desde $5,43 \%$ hasta $0,74 \%$ (abogados sobre total de denuncias), y de $1,52 \%$ al inicio del sistema hasta valores cercanos a 0 en los últimos dos años (abogados sobre expedientes con sanciones).

De acuerdo a esta evolución en la cantidad de abogados sancionados, la variación del número de abogados y la cantidad de sanciones aplicadas puede dividirse en dos períodos bien diferenciados (2002-2010) y (2011-2014). En el primer período (2002-2010), el promedio de sanciones es de 13 por año, y considerando el número de matriculados, la tasa de sanciones por abogados es de 1 sanción cada 136 abogados. En cambio, en los últimos cuatro años, el promedio de sanciones no llega a 3 sanciones por año. Esta cifra tan pequeña, sumada al aumento en la cantidad de matriculados en el mismo período (124 \% más del promedio de 2002-2010), hace que la tasa de abogados por sanción ascienda a 921 abogados por sanción (si no se considera 2014), o a 1228, si no se considera el año 2014, donde no hubo sanciones. 


\subsection{Resultados de los procedimientos según el denunciante}

Los principales descubrimientos de la investigación se vinculan con la variación de los porcentajes de finalización y de aplicación de sanciones en función de la variable denunciante y tipo de infracción.

Hemos visto que considerando el total de las denuncias (412), finalizaron $267(65 \%)$ con un porcentaje de sanciones aplicadas del 31,80 \% (131 expedientes). Pero este resultado global esconde una diferencia altamente significativa entre los expedientes y su resultado considerando el denunciante. Para apreciar mejor estas divergencias, creo necesario distinguir los expedientes diferenciando los iniciados por clientes, tribunales, colegas, otros organismos públicos y particulares y el caso de autodenuncia, como se aprecia en la siguiente tabla.

Tabla 8

Denuncias iniciadas y terminadas según el denunciante (2002-2014)

\begin{tabular}{|lcccc|}
\hline Denunciante & \multicolumn{2}{c}{ Iniciados } & \multicolumn{2}{c|}{ Terminados } \\
\hline Clientes & 166 & $40 \%$ & 106 & $\mathbf{6 4} \%$ \\
Administración de Justicia & 159 & $39 \%$ & 122 & $77 \%$ \\
Colegas & 51 & $12 \%$ & 26 & $51 \%$ \\
Otros organismos públicos & & & & \\
y otros particulares & 35 & $8 \%$ & 12 & $34 \%$ \\
Autodenuncia & 1 & $0 \%$ & 1 & $100 \%$ \\
\hline Total & 412 & $100 \%$ & 267 & $65 \%$ \\
\hline
\end{tabular}

Fuente: Elaboración propia en base a registros del Tribunal de Disciplina del Colegio de Abogados de Corrientes.

Los resultados demuestran diferencias significativas en los procedimientos iniciados por clientes en conflictos con sus abogados en relación con los que se inician por actuación de los órganos jurisdiccionales. Si bien ambas categorías acumulan números similares de denuncias (166 de clientes contra 159 de tribunales), los resultados considerando la finalización y la aplicación de sanciones son muy diferentes. En el caso de las denuncias realizadas por clientes, los procedimientos solo terminaron en el $64 \%$, contra el $77 \%$ de los iniciados por denuncias de los tribunales. El porcentaje de procedimientos finalizados por denuncias de los magistrados es también 
superior al de los iniciados por colegiados y por otros organismos públicos, que solo concluyeron en el $51 \%$ y $34 \%$, respectivamente.

Si se desglosa el total de las sanciones aplicadas (131 expedientes) por iniciador la divergencia en los resultados es aún mayor.

Tabla 9

Porcentajes de sanciones por denunciante (2002-2014)

\begin{tabular}{|lcccc|}
\hline Denunciante & \multicolumn{2}{c}{ Iniciados } & \multicolumn{2}{c|}{ Terminados } \\
\hline Clientes & 166 & $40 \%$ & 29 & $\mathbf{1 7 \%}$ \\
Administración de Justicia & 159 & $39 \%$ & 89 & $\mathbf{5 6 \%}$ \\
Colegas & 51 & $12 \%$ & 10 & $20 \%$ \\
Otros organismos públicos & 35 & $8 \%$ & 3 & $9 \%$ \\
y otros particulares & 1 & $0 \%$ & 0 & $0 \%$ \\
Autodenuncia & 412 & $100 \%$ & 131 & $32 \%$ \\
\hline Total & & & & \\
\hline
\end{tabular}

Fuente: Elaboración propia en base a registros del Tribunal de Disciplina del Colegio de Abogados de Corrientes.

Los expedientes iniciados por clientes representan solo un $17 \%$ de sanciones aplicadas sobre expedientes iniciados (29 expedientes), contra un 56 $\%$ de sanciones en los casos de expedientes iniciados por denuncias realizadas por los tribunales (89 expedientes). Así, el porcentaje de sanciones aplicadas en expedientes iniciados por quejas de los tribunales más que triplica a los que son iniciados por clientes y explica el $68 \%$ del total de las sanciones aplicadas (89 sobre 131).

\subsection{Tipo de infracciones}

Las infracciones denunciadas ante el Tribunal de Disciplina son muy diversas. Para su mejor comprensión, las he clasificado atendiendo al contenido de la denuncia. Cuando se consideran cuáles son las consecuencias de los procedimientos, se advierten diferencias muy significativas en los resultados finales de los procedimientos (sanción o no sanción). 
MAURICIO GOLDFARB

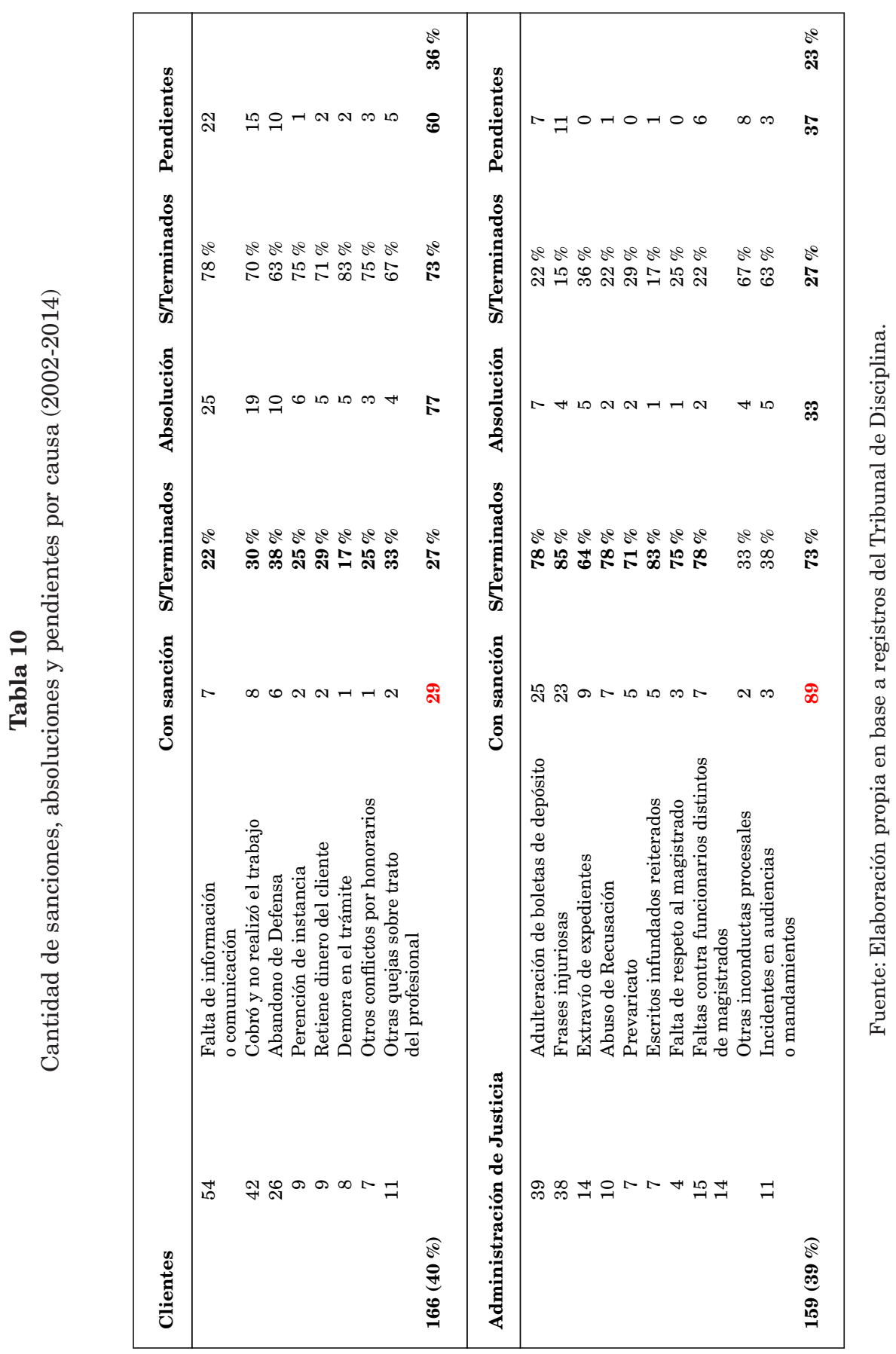


ÉTICA PROFESIONAL DE LOS ABOGADOS. TEORÍA Y PRAXIS EN LA PROVINCIA...

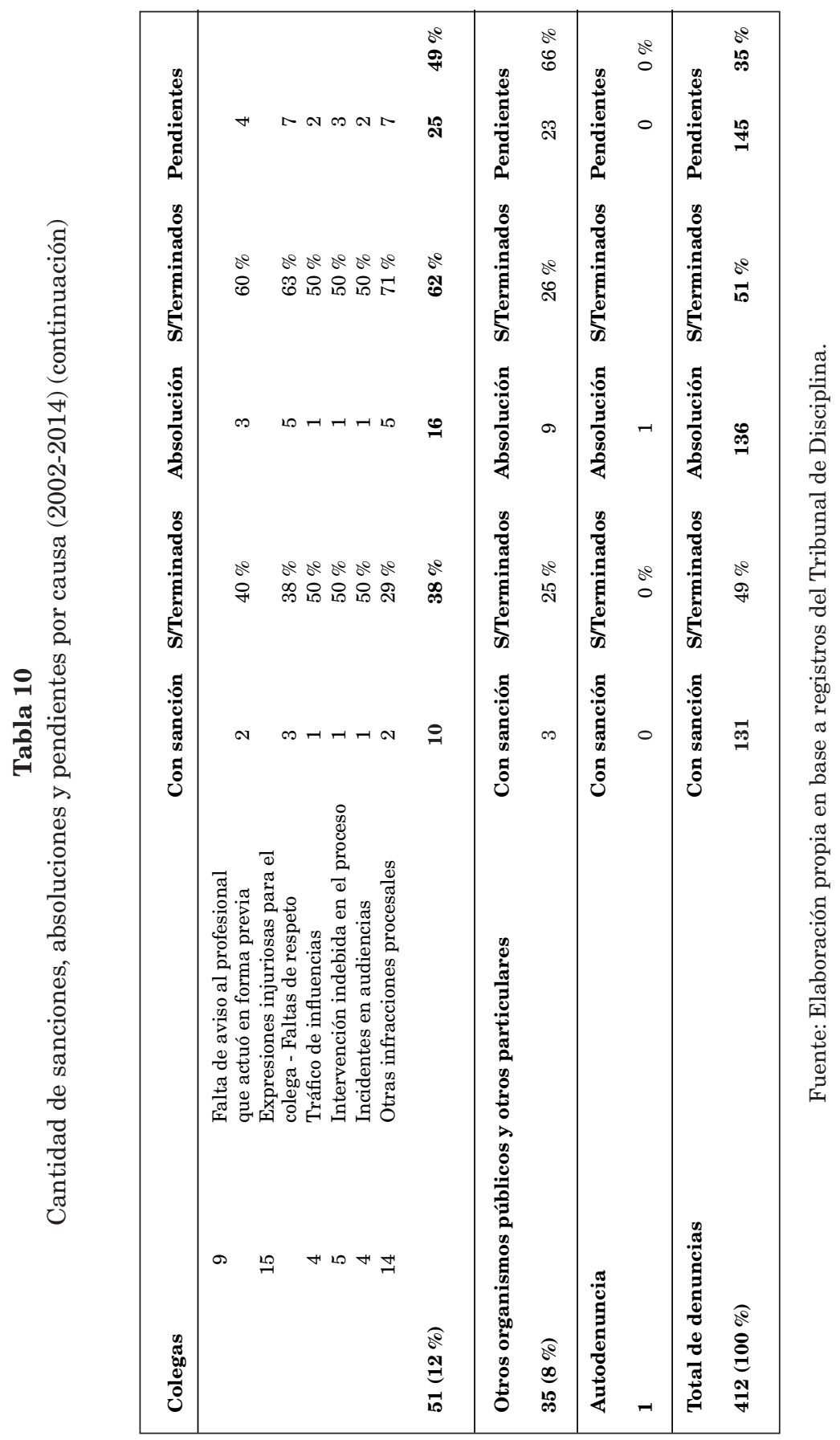


Estos valores permiten apreciar la diferente consideración del sistema para con las denuncias, considerando la persona del denunciante. En la tabla anterior se puede apreciar con gran detalle el tipo de infracción denunciada y las consecuencias del procedimiento iniciado. Así, se puede advertir que cuando la denuncia es formulada por clientes la tasa de sanciones es baja (entre el $17 \%$ y el $38 \%$ del total de expedientes terminados), comparado con el caso de las sanciones producto de denuncias de órganos jurisdiccionales (mínimos de $33 \%$ y hasta $85 \%$, con un promedio del $73 \%$ del total de expedientes terminados).

\section{Discusión de los resultados}

Los hallazgos más significativos del trabajo de campo se vinculan con la clara tendencia a una mayor sanción a infracciones cometidas contra la Administración de justicia, en comparación con los conflictos surgidos de la relación cliente-abogado. A pesar de que las denuncias formuladas por clientes y por la administración de justicia tienen porcentajes equivalentes (alrededor del $40 \%$ cada uno), cuando se considera el resultado final, la tasa de sanciones en los casos de procedimientos iniciados por denuncias de juzgados más que triplica a la de los procedimientos iniciados por clientes disconformes con sus letrados, como puede apreciarse en la siguiente tabla.

Tabla 11

Procedimientos por denunciante, terminados y con sanciones (2002-2014)

\begin{tabular}{|lcccccc|}
\hline Denunciante & Iniciados & \multicolumn{2}{l|}{ Terminados } & Sanciones \\
\hline Cliente & 166 & $\mathbf{4 0 , 2 9 \%}$ & $\mathbf{1 0 6}$ & $\mathbf{6 3 , 8 6} \%$ & 29 & $22,14 \%$ \\
Adm. Justicia & 159 & $\mathbf{3 8 , 5 9 \%}$ & $\mathbf{1 2 2}$ & $\mathbf{7 6 , 7 3 \%}$ & 89 & $\mathbf{6 7 , 9 4 \%}$ \\
Colegas & 51 & $12,38 \%$ & 26 & $\mathbf{5 0 , 9 8 \%}$ & 10 & $7,63 \%$ \\
$\begin{array}{l}\text { Otros organismos } \\
\text { públicos }\end{array}$ & 35 & $8,50 \%$ & 12 & $\mathbf{3 4 , 2 9 \%}$ & 3 & $2,29 \%$ \\
Autodenuncia & 1 & $0,24 \%$ & 1 & $100,00 \%$ & 0 & $0,00 \%$ \\
\hline Total & 412 & $100,00 \%$ & 267 & $\mathbf{6 4 , 8 1 \%}$ & 131 & $\mathbf{3 1 , 8 0 \%}$ \\
\hline
\end{tabular}

Fuente: Elaboración propia en base a los registros del Tribunal de Disciplina.

Entiendo que las razones que explicarían este comportamiento son múltiples. En primer término, el procedimiento disciplinario considera y trata de igual modo -al menos en su inicio y desde un punto de vista formal- las denuncias realizadas por clientes, por colegas y por organismos 
públicos. De esta manera, trata como iguales a quienes no son iguales (clientes - abogados - poder público).

Sin embargo, es claro que los clientes no cuentan con todas las herramientas de conocimiento jurídico y de estrategia procesal para dar comienzo e instar el trámite disciplinario, trámite que ni siquiera les otorga el carácter procesal de parte, lo que lo coloca totalmente fuera del procedimiento, sin una justificación adecuada ${ }^{39}$. Por otra parte, las infracciones éticas que sufren los clientes tienen una mayor cifra sin denuncias (cifra negra) explicada por la escasa difusión en la sociedad siquiera de la existencia del sistema disciplinario profesional. Esta cifra negra pudo ser verificada en el curso de la investigación, en el marco de las entrevistas a la Secretaria del Tribunal. Consultada sobre la cuestión, la empleada (también abogada) manifestó: "[...] muchas personas vienen a quejarse, pero cuando se les entrega el formulario de denuncia y se les explica que no les van a devolver su dinero, se van y no hacen la denuncia". A ello se suma que la afectación de sus derechos resulta muchas veces de muy difícil prueba, especialmente por falta de documentación o porque esta queda en poder del propio letrado.

$\mathrm{El}$ caso de las denuncias entre colegas es distinto. Al menos desde el punto de vista teórico, cuentan con conocimientos del sistema superiores a los de sus clientes, y -también teóricamente- en un plano similar al de los órganos públicos. Pero lo cierto es que los poderes públicos, y en especial los magistrados judiciales, tienen la posibilidad de tomar decisiones que afectan de manera directa el ejercicio profesional, en especial durante el curso de los procesos. Ello sin contar con otras medidas indirectas, a veces más o menos sutiles, que pueden traslucirse en las decisiones que el magistrado adopta durante toda la causa y perjudicar al abogado y los intereses que este representa.

Las denuncias formuladas por los juzgados se acompañan de prueba documental, casi siempre obrante en instrumentos públicos, que no admiten prueba en contrario, salvo los casos de excepción previstos en la norma de fondo. Además, las denuncias derivadas por la Administración de Justicia en su casi totalidad son el resultado de una sanción previa de orden procesal, en la que se declara acreditada la existencia de un comportamiento contrario a las reglas del buen ejercicio profesional. La sanción posterior a la aplicada por el órgano jurisdiccional -muchas veces el máximo tribunal del orden provincial-implica también una especie de culto o respeto reverencial a la autoridad judicial. En ese sentido, es evidente que más allá de la declarada independencia del sistema sancionatorio profesional, y como

39 Martínez Yáñez, N. (2001). "Problemas jurídico-prácticos de la figura del denunciante en el procedimiento administrativo sancionador”. Revista Xurídica Galega, № 33. 
resulta de la lectura de las sentencias condenatorias del Tribunal de Disciplina a las que se tuvo acceso en el marco de esta investigación, subsiste una especie de sumisión (y mera ratificación) a la actuación jurisdiccional.

Por ello, si el Tribunal de Disciplina solo aplica sanciones en base a expedientes iniciados por denuncias de los Tribunales judiciales, se convierte en un apéndice y mero repetidor (incluso solo parcial) de las decisiones del Poder Judicial, cercenando uno de los aspectos más importantes de su labor: la tutela del correcto ejercicio profesional y la protección de los derechos de los ciudadanos.

Otro resultado especialmente relevante es que durante todo el período estudiado no existe ni un solo caso de abogado al que se haya aplicado la sanción de exclusión de la matrícula. ¿Cuáles son las causas de la falta de aplicación de esta sanción? Una primera explicación podría ser la inexistencia de faltas de tal gravedad que merezcan la sanción de exclusión. Sin embargo, considerando el número de abogados, la cantidad y complejidad de los vínculos con sus clientes y los otros elementos del sistema judicial y administrativo, esta explicación parece poco probable. Como resultado del examen de más de los 420 expedientes tramitados, me inclino por sostener que el sistema disciplinario profesional funciona en la realidad como uno de intensidad media, es decir, un conjunto de procedimientos preparados para detectar, considerar y sancionar un tipo particular de faltas: aquellas que revisten cierta gravedad (media), dejando de lado las infracciones menores y también las máximas.

Además, aparece otro obstáculo insalvable que resulta del propio Decreto Ley de colegiación. Esta norma exige para la sanción de exclusión de la matrícula la concurrencia de dos terceras partes del total de los miembros del Tribunal. Sin embargo, el Reglamento Procesal, al encomendar la investigación a la Sala de radicación del denunciado y luego el juzgamiento a otra Sala, excluye del Tribunal en pleno a cuatro miembros. Por lo tanto, los seis miembros restantes $(60 \%)$ no pueden en ningún caso llegar a la mayoría exigida $(66,66 \%)$, con lo cual la sanción de exclusión resulta de imposible ejecución. El resultado es, entonces, que en trece años de funcionamiento del sistema no se aplicó la sanción de exclusión a ningún abogado a pesar de que varios han sido sancionados de manera reiterada con suspensiones de 1 año en el ejercicio profesional. Esta limitación debe ser modificada a la brevedad posible, so pena de mantener como letra muerta la sanción de exclusión de la matrícula.

En un examen global de los expedientes disciplinarios se puede verificar que las infracciones denunciadas, así como las que luego dieron lugar a sanción son, salvo algunas excepciones, de una gravedad intermedia. No se han denunciado, ni sancionado infracciones de una gravedad escandalosa ni que involucren bienes o intereses patrimoniales de gran significación. El 
Tribunal de Disciplina ha impuesto como sanción típica la suspensión en el ejercicio de la profesión (112 suspensiones sobre un total de 131 expedientes terminados con sanciones). La moda de la sanción ha sido la suspensión por menos de 30 días (94 sobre el total de 112).

Esta cuestión tiene dos aspectos: Por un lado, muchas de las sanciones son aplicadas por faltas que podemos considerar como menores, como incidencias procesales, discusiones o escritos que no guardan las formas. Por el otro, en el caso de infracciones más graves en sí, pero no significativas en relación a los bienes tutelados. Por ejemplo, la adulteración de las boletas de depósito de tasas de justicia -la falta más sancionada, con 25 expedientes finalizados en sanción de suspensión- consistía, al menos en 4 casos que son típicos, en agregar un 1 y pretender que un pago de 2 pesos se transforme en uno de 12. Otro ejemplo es el caso de cobro de anticipos sin que luego se realice la gestión administrativa o judicial, en los que las sumas denunciadas como retenidas por los clientes no eran cuantiosas (en algunos casos solo algunos cientos de pesos).

En el marco de futuras investigaciones, sería muy interesante que se examinara el comportamiento de las variables en Tribunales de Disciplina de abogados de otras provincias. Estimo como muy probable que, si se examinan estas mismas variables, los resultados muestren una tendencia similar (fuerte prevalencia de sanciones propuestas por los tribunales por sobre las denunciadas por clientes). Los porcentajes de sanción o de prevalencia pueden ser diferentes, considerando las variables de tipo sociológico que marcan la idiosincrasia de cada jurisdicción. Pero al ser las mismas las condiciones de inferioridad y falta de motivación del cliente para denunciar, en comparación con la de los tribunales, se puede predicar que los resultados mostrarán la misma tendencia.

Para finalizar, quiero resaltar que en el fundamento mismo del sistema de colegiación pública se encuentra la delegación que el Estado hace a los propios abogados del control sobre el correcto ejercicio profesional, de modo que sean los mismos colegas quienes sancionen la violación a las normas del buen desempeño. Esta potestad sancionatoria conlleva la posibilidad de excluir de la matrícula y privar del ejercicio profesional al colega que comete faltas graves. Sin embargo, en las entrevistas realizadas a los miembros del Tribunal existió coincidencia en que los propios abogados resisten la aplicación del sistema disciplinario. Esta afirmación se ve también corroborada por el bajo porcentaje (12\%) de procedimientos iniciados por denuncias de profesionales, que solo explican el $8 \%$ de las sanciones aplicadas en el período. Sin dudas, el fortalecimiento del sistema disciplinario solo tendrá lugar cuando los propios abogados confíen en su funcionamiento y eficacia. 


\section{MAURICIO GOLDFARB}

\section{Bibliografía}

AA. VV. (2006). “Por qué es importante que se brinde un espacio al tratamiento de temas relacionados con la Ética y Responsabilidad Profesional de los Abogados?”. Revista Ius et Veritas, $\mathrm{N}^{\circ} 33$.

Altamira Gigena, J. (2008). Lecciones de Derecho Administrativo. $2^{\mathrm{a}}$ ed. Córdoba. Advocatus.

Andruet, A. (2001). Ejercicio de la abogacía y deontología del Derecho. Córdoba. Alveroni.

Balbín, C. (2014). Tratado de Derecho Administrativo. Buenos Aires. La Ley.

Camps, C. (2002). "Derecho al debido proceso y ética profesional". JA, 2002-II, fascículo $\mathrm{N}^{\circ} 10$.

Carnota, W. (2016). Instituciones de Derecho Público. $2^{\mathrm{a}}$ ed. Buenos Aires. La Ley.

Ciuro Caldani, M. (2019). Manual de ética de la abogacía. Buenos Aires. Ediciones SAIJ.

Dromi, R. (2009). Derecho Administrativo, $12^{\text {a }}$ ed. act. Buenos Aires-Madrid-México. Ciudad Argentina - Hispania Libros.

Fucito, F. (2000). "El pago de la matrícula profesional y la ética del abogado". $L L$ 25-9-2000.

García de Enterría, Eduardo - Fernández, T. (2003). Curso de Derecho Administrativo. Madrid. Civitas.

García Pullés, F. (2003). "Derecho Administrativo Sancionador y algunas notas del régimen disciplinario del empleo público", JA 2003-IV suplemento del fascículo 9.

Gelli, M. (2008). Constitución de la Nación Argentina. Comentada y concordada. Buenos Aires. La Ley.

Gordillo, A. (1996). "La prescripción penal de una sanción administrativa". LL, 1996A, 625 .

Ivanega, M. (2013). Cuestiones de potestad disciplinaria y derecho de defensa. $2^{\mathrm{a}}$ ed. Actualizada. Buenos Aires. Ediciones Rap.

Kemelmajer de Carlucci, A. (2005). "Reflexiones sobre las normas deontológicas y la responsabilidad del abogado". Revista de Derecho de Daños 2005-1. Santa Fe. Rubinzal Culzoni.

Malamud, H.; Muñoz, H.; Malamud, J. (2014). Ética y Disciplina de la Abogacía Bonaerense. Buenos Aires. Cathedra Jurídica.

Maljar, D. (2004). El Derecho Administrativo Sancionador. Buenos Aires. Ad. Hoc.

Martínez Yáñez, N. (2001). "Problemas jurídico-prácticos de la figura del denunciante en el procedimiento administrativo sancionador". Revista Xurídica Galega, $\mathrm{N}^{\circ} 33$.

Monti, L.; Muratorio, J. (1993). "La aplicación de la Ley Nacional de Procedimientos Administrativos a los actos de los entes públicos no estatales”. REDA, N 14 . Buenos Aires. Depalma.

Morello, A.; Berizonce, R. (1981). Abogacía y Colegiación. Buenos Aires. Hammurabi. Nieto García, A. (2012). Derecho Administrativo Sancionador. $5^{a}$ ed. Madrid. Tecnos. Parry, A. (1940). Ética de la abogacía. Buenos Aires. Editorial Jurídica Argentina. 
Salgán Ruiz, L. (2011). "Las sanciones de plano y la problemática de su aplicación por la Administración Pública en el régimen disciplinario del contrato de empleo público. Avances y retrocesos del derecho administrativo disciplinario". Revista Argentina del Régimen de la Administración Pública -Rap: 395, Buenos Aires, Ediciones Rap, 2012.

Serna Orts, V. (2013). La relación del abogado con el cliente: La confianza y actuaciones que la traicionan. Revista de la Facultad de Ciencias Sociales y Jurídicas de Elche. Volumen I. Número 9.

Sesin, D. (1996). Discrecionalidad administrativa y conceptos jurídicos indeterminados. Buenos Aires. Ciencias de la Administración.

Sesin, D.; Chicacchiera Castro, P. (2012). Los Colegios Profesionales - Régimen Jurídico Público. Santa Fe. Rubinzal Culzoni Editores.

Stiglitz, R. (2005). "Seguro contra la responsabilidad profesional". Revista de Derecho de Daños 2005-1. Santa Fe. Rubinzal Culzoni.

Vigo, R. (h). (1990). Ética del Abogado. Buenos Aires. Abeledo Perrot. 